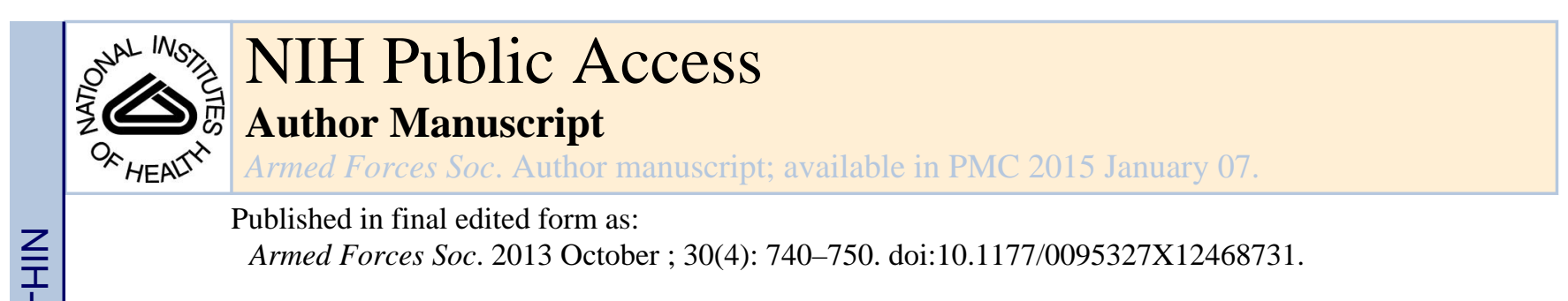

\title{
A Note on Disappearing Veterans
}

\author{
Jay Teachman ${ }^{1}$ \\ ${ }^{1}$ Western Washington University, Bellingham, WA, USA
}

\section{Abstract}

In this research note, the rapid decline of the veteran population in the United States from 1980 to 2010 is outlined. The decline in the veteran population has been accompanied by an increasing concentration of veterans in smaller, more rural counties, often surrounding military bases. The result is that there has been a consistent increase in the residential segregation of veterans from the nonveteran population.

\section{Keywords}

veterans; geographic distribution

In a speech presented at Duke University on September 29, 2010, the then Secretary of Defense Robert Gates noted a growing divide between the military and the civilian population that it serves. The divide Secretary Gates spoke about was not the result of political strife or rancor surrounding the wars in Iraq and Afghanistan. Rather, the divide was posited to be a consequence of misunderstanding and suspicion that is the result of minimal social interaction that flows from the growing geographic and social isolation of the military. According to Secretary Gates, "with each passing decade, fewer and fewer Americans know someone with military experience in their family or social circle." ${ }^{1}$ In this article, descriptive evidence is provided that Secretary Gates was correct in his assessment that military and civilian populations are increasingly isolated from each other. Other commentators have noted the importance of this form of residential segregation for civilmilitary relations. ${ }^{2,3}$ Evidence is provided for the growing residential segregation of the veteran-nonveteran populations using data for the period 1980-2010. It was found that the proportion of America's population that has military experience has declined sharply over time and that the geographic distribution of veterans has become increasingly concentrated.

(C) The Author(s) 2012

Corresponding Author: Jay Teachman, Department of Sociology, Western Washington University, Bellingham, WA 98225, USA jay.teachman@wwu.edu.

Declaration of Conflicting Interests

The author declared no potential conflicts of interest with respect to the research, authorship, and/or publication of this article. 


\section{What do We Know about the Prevalence and Geographic Distribution of Veterans?}

There are two basic components to change in the exposure of nonveterans to veterans. The first component is the absolute number of veterans compared to the number of nonveterans. The second component is the geographic distribution of veterans compared to nonveterans. The extent to which the veteran population becomes a smaller proportion of the population and is increasingly concentrated means that there will be less contact between the veteran and nonveteran populations.

The number of veterans in the United States has been declining over time. In 1980, there were more than 28 million veterans, a number that decreased to 22 million in $2010 .{ }^{4}$ The decrease in the number of veterans has occurred because of the continued mortality of the very large cohort of World War II veterans and the decreasing size of the active duty military force. For example, in 1980, there were over 2 million men and women serving on active duty, compared to about 1.4 million in 2010. ${ }^{5}$ Over the same period, the total population of the United States increased from 226 million to 308 million. The decrease in the number of veterans means that the percentage of the population that is veteran dropped from just over 12 percent in 1980 to just over 7 percent in 2010. What we do not know is whether this decrease in the number of veterans has occurred uniformly across the United States. By itself, however, the decline in the number of active-duty service members and veterans means that the likelihood of civil-military interaction has decreased.

There is surprisingly little published information pertaining to the geographic distribution of veterans. Information from the 2000 census indicates that veterans are more likely to be found in the South and Midwest, particularly in rural and nonmetropolitan areas. ${ }^{6}$ These are also the areas from which most military recruits are drawn. ${ }^{7}$ What is not known is how the distribution of veterans compares to the distribution of the nonveteran population and how this comparison may have changed across time.

There are good reasons, however, for expecting that veterans will be dispersed differently than their civilian counterparts. First, we know that veterans are more likely to migrate than nonveterans. ${ }^{8,9}$ Second, veterans have demonstrated a preference to settle in areas where there is a major military presence. ${ }^{10}$ In part, this may be a function of the preferences of military retirees and may not extend to all veterans. Unfortunately, data are not available to consider this possibility. Veterans are also more likely than nonveterans to migrate to warmer climates in the South such as Arizona, Florida, North Carolina, and Texas. ${ }^{11}$ Moreover, there has been an increasing concentration of military bases in the United States over the past thirty years due to base closures and realignments. ${ }^{12}$ Thus, not only are there fewer veterans to be spread over any given geographic area, these veterans may have been making migration choices that are far from random and different from those of nonveterans.

\section{Data and Method}

The primary data used in this research note are taken from the US Counties Data File Information available from the US Census. ${ }^{13}$ There are 3,141 counties or county equivalents 
in the United States. Data are taken from 1980, 1990, 2000, and 2010. After excluding 10 counties (mainly in Alaska) that have consistently small populations and no veterans, 3131 counties are examined using estimates of the veteran and nonveteran populations. The period 1980-2010 is emphasized because it is a span of time corresponding to the full implementation of the all-volunteer force and the decline in the number of active-duty service members and veterans. It also corresponds to the period during which the unusually large cohort of WWII veterans began to experience heightened mortality. As noted earlier, it is not possible to separate veterans according to length of service. Also lacking are data on other characteristics of veterans such as race and gender. It may be the case that the distribution of veterans varies according to these characteristics.

Counties are the units of analysis because they are the smallest geographic unit for which comparable, longitudinal information about veterans is available. Moreover, counties have provided the basis for estimating segregation across a number of other characteristics, especially race. ${ }^{14} \mathrm{~A}$ disadvantage of counties, however, is that they may not best represent the geographic area across which patterns of social interaction occur. Counties vary considerably in size, with larger counties less likely to constitute units where social interaction among a majority of residents. That said, however, counties do form relatively stable bureaucratic units for making longitudinal comparisons. In addition, my purpose is less focused on measuring segregation precisely at a point in time than it is on measuring change across time in geographic distribution. It is reasonable to assume that an increase in residential segregation at the county level will be accompanied by an increase in residential segregation across smaller units of geography.

Consistent with the notion that change in exposure to veterans is a function of both the proportion of veterans in a population and the distribution of veterans, emphasis is placed on two dimensions of the veteran population. First, the proportion of a county that reported being a veteran and how these proportions have changed across time are examined. Second, indices of dissimilarity between veteran and nonveteran populations and how they have changed across time are calculated.

\section{Results}

\section{Change in the Prevalence of Veterans}

Figure 1 is a box and whisker plot of the proportion of a county's population that is a veteran. In 1980, the median proportion was .118. By 2010, this value had fallen by 26 percent to .087 . The pace at which the proportion of veterans in a county population is falling appears to be increasing. Between 1980 and 1990, the veteran population fell by an average (median) of 4.6 percent. Between 1990 and 2000, the average decline was 8.5 percent, and between 2000 and 2010, the average decline was 15.5 percent. Thus, not only is the proportion of veterans in a county falling, but it is doing so at an accelerating pace.

Table 1 indicates the proportion of a county that is a veteran according to size of population. Size is defined by population quartiles in each of the years considered. The proportion of a county that is veteran is disaggregated by size of the population for two reasons. First, as indicated earlier, ceteris paribus, smaller counties allow more interaction between veterans 
and nonveterans. Second, previous research has indicated that veterans prefer more rural counties, which tend to be smaller. Disaggregating indices of dissimilarity according to size allows this proposition to be tested.

In each quartile of size, the proportion of veterans declined over time. The decline in the proportion of veterans was particularly large for the largest counties (.128 to .080) and smaller for the smallest counties (.115 to .095). Indeed, a slightly positive distribution of the proportion of veterans according to county size in 1980 turned into a slightly negative relationship between these two variables by 2010 . This pattern is congruent with the preference of veterans for smaller, more rural counties. Indeed, by 2010, the value of the third quartile for the largest counties was approximately equal to the value of the median for the smallest counties. In 1980, not only was the value of the third quartile for the largest counties larger than the median for the smallest counties, it was larger than the third quartile for these counties.

The values shown in Table 1 suggest that 10 percent indicates a relatively dense population of veterans (at or above the median for all counties in 2000 and 2010). In Table 2, the number of counties in which more than 10 percent of the population is a veteran is shown. Also shown is the number of counties in which more than 15 percent of the population is a veteran, which according to Table 1 is well above the third quartile for all counties since 1980. In 1980, 2,509 counties ( 80 percent of all counties) had more than 10 percent veterans. The figures for 1990, 2000, and 2010 are 2,308 (73 percent of counties), 1,722 (55 percent of counties), and 828 ( 26 percent of counties). The number of counties with more than 15 percent veteran fell from 145 in 1980 to 49 in 2010. If restricted to larger counties (population more than 100,000), the number of counties with more than 15 percent veterans decreased by more than half from 20 in 1980 to 9 in 2010. Moreover, the 9 counties in 2010 were concentrated in just three states (five in Florida, three in Virginia, and one in Washington State), each within reasonable proximity to a major military installation. ${ }^{15}$

The decline in the relative prevalence of veterans from 1980 to 2010 is graphically represented in Figures 2 to 5. The rapid decline in the number of counties with a high percentage of veterans is clearly evident. By 2010, large swaths of the United States held few veterans (less than 8 percent). The drop in the percentage of veterans is particularly dramatic for the Northeast and the western third of the country. By 2010, many of the remaining high-density counties were often associated with nearby military installations (e.g., Pensacola Naval Air Station in Florida, Mountain Home Air Force Base in Idaho, Norfolk Naval Shipyard in Virginia, Holloman Air Force Base in New Mexico, Nellis Air Force Base in Nevada, Kitsap Naval Station in Washington State, Fort Bragg in North Carolina, Fort Rucker in Alabama, and Fort Hood in Texas).

\section{Change in the Distribution of Veterans}

In addition to fewer veterans, there has been substantial change in the distribution of veterans. Table 3 shows indices of dissimilarity for the distribution of veterans and nonveterans across counties for the nation as a whole. The index of dissimilarity measures the degree of evenness of two groups spread across geographic areas (here counties). It indicates the proportion of one group that would have to move in order to match the 
geographic distribution of the other group. Higher values of the index indicate a higher degree of residential segregation between the two groups. As can be seen in Table 3, there has been substantial increase in the index of dissimilarity across time. In 1980, the index of dissimilarity was .064, a value that more than doubled to .144 in 2010 . The indices of dissimilarity also increased across counties of different sizes. However, the increase was particularly strong among the largest counties where dissimilarity values increased from . 057 to .147 . As was the case for the proportion of a county population that is a veteran, the relationship between county size and index of dissimilarity changed over time. Whereas smaller counties registered larger values of the dissimilarity index in 1980, the converse was true in 2010. Again, this pattern is consistent with the increasing concentration of veterans in smaller, rural counties.

There is also considerable variation in county-based indices of dissimilarity when estimated for states. Figure 6 shows the distribution of these indices of dissimilarity across states for the years 1980-2010. In addition to the increase in the indices of dissimilarity over time, there is evidence for greater variability in the indices across time. That is, there is greater distance between the highest and lowest values, as well as greater distance between first and third quartile values. This pattern suggests that not only are veterans becoming more segregated within states, but that states themselves are becoming increasingly dissimilar with respect to the distribution of veterans. Change from 1980 to 1990 appears to be somewhat slower than was the case for the following two-decade changes.

Over the period 1980-2010, only four states experienced a decline in their dissimilarity indices (Alaska, Kentucky, New Mexico, and West Virginia), whereas twenty-three states experienced at least a doubling in their indices (results not shown), and the average percentage increase in the indices of dissimilarity was 117.4. Four states experienced an increase of more than 200 percent in their indices of dissimilarity (Connecticut, Illinois, Rhode Island, and Washington). In Connecticut, the level of dissimilarity increased by more than fivefold between 1980 and 2010.

\section{Discussion and Conclusion}

In this research note, it is demonstrated that the number of veterans in the United States has decreased dramatically over the past 30 years. In addition, veterans have become more geographically concentrated. The result is that there is increasing residential segregation between the veteran and nonveteran populations. Although beyond the scope of this note to assess, the increasing geographic concentration of veterans may hold consequences for civil-military relations.

\section{Acknowledgments}

Funding

The author received no financial support for the research, authorship, and/or publication of this article. 


\section{Biography}

Jay Teachman is currently a professor in the Department of Sociology at Western Washington University. His research interests focus on the relationship between military service and subsequent life course outcomes for men and women. Recent publications include: M. Whyman, M. Lemmon, and J. Teachman. 2011. "Non-Combat Military Service in the United States and its Effects on Depressive Symptoms among Men." Social Science Research 40:695-703; Teachman, Jay. 2010. "Are Veterans Healthier? Military Service and Health at Age 40 in the All-volunteer Era." Social Science Research 40:326-335; J. Teachman and L. Tedrow. 2008. "Divorce, Race, and Military Service: More than Equal Pay and Equal Opportunity.” Journal of Marriage and Family 70:1030-1044.

\section{Notes}

1. Department of Defense. [May 8, 2012] Remarks by Secretary Gates at Duke University, North Carolina. 2010. http://www.defense.gov/transcripts/transcript.aspx? transcriptid 4691

2. Feaver, Peter; Kohn, Richard. Soldiers and Civilians: The Civil-Military Gap and American National Security. MIT Press; Boston, MA: 2001.

3. Nielson, Suzanne; Snider, Don. American Civil-Military Relations: The Soldier and the State in a New Era. The Johns Hopkins University Press; Baltimore, MD: 2009.

4. US Department of Veteran Affairs. [May 15, 2011] Veteran Population. 2012. http://www.va.gov/ vetdata/Veteran_Population.asp

5. US Census Bureau. Statistical Abstract of the United States. US Government Printing Office; 2012.

6. Richardson, Christy; Waldrop, Judith. Veterans: 2000. US Government Printing Office; 2003.

7. Segal, David; Segal, Mady. America's Military Population, Population Bulletin. 2004; 59:4.

8. Bailey, Amy. Race, Place, and Veteran Status: Migration among Black and White Men, 1940-2000. Population Research \& Policy Review. 2011; 30(5):701-28.

9. Cowper, Diane; Longino, Charles; Kubal, Joseph; Manheim, Larry; Dienstfrey, Stephen; Palmer, Jill. The Retirement Migration of U.S. Veterans, 1960, 1970, 1980, and 1990. Journal of Applied Gerontology. 2000; 19(2):123-37.

10. Bailey, Amy. Military Employment and Spatial Mobility Across the Life Course. In: Wilmoth, Janet; London, Andrew, editors. Military Service in Lives. Routledge; New York: forthcoming

11. Diane Cowper, Charles Longino; Joseph Kubal, Larry Manheim; Dienstfrey, Stephen; Palmer, Jill. The Retirement Migration of U.S. Veterans, 1960, 1970, 1980, and 1990.

12. Office of the Deputy Under-Secretary of Defense, Installations, and Environment. [May 15, 2012] U.S. Military Installations, Ranges, and Training Areas. http://www.acq.osd.mil/ie/download/bsr/ BSR2012Baseline.pdf

13. US Census Bureau. [June 12, 2012] USA Counties Data File Information. http://www.census.gov/ support/USACdataDownloads.html\#VET

14. Douglas Massey, Jonathan Rothwell; Domina, Thurston. The Changing Bases of Segregation in the United States. The Annals of the American Academy of Political and Social Science. Nov. 2009 626:74-90.

15. The counties are Charlotte, Citrus, Okaloosa, Escambia, and Santa Rosa in Florida; Stafford, Hampton, and Virginia Beach in Virginia; and Kitsap in Washington State. 


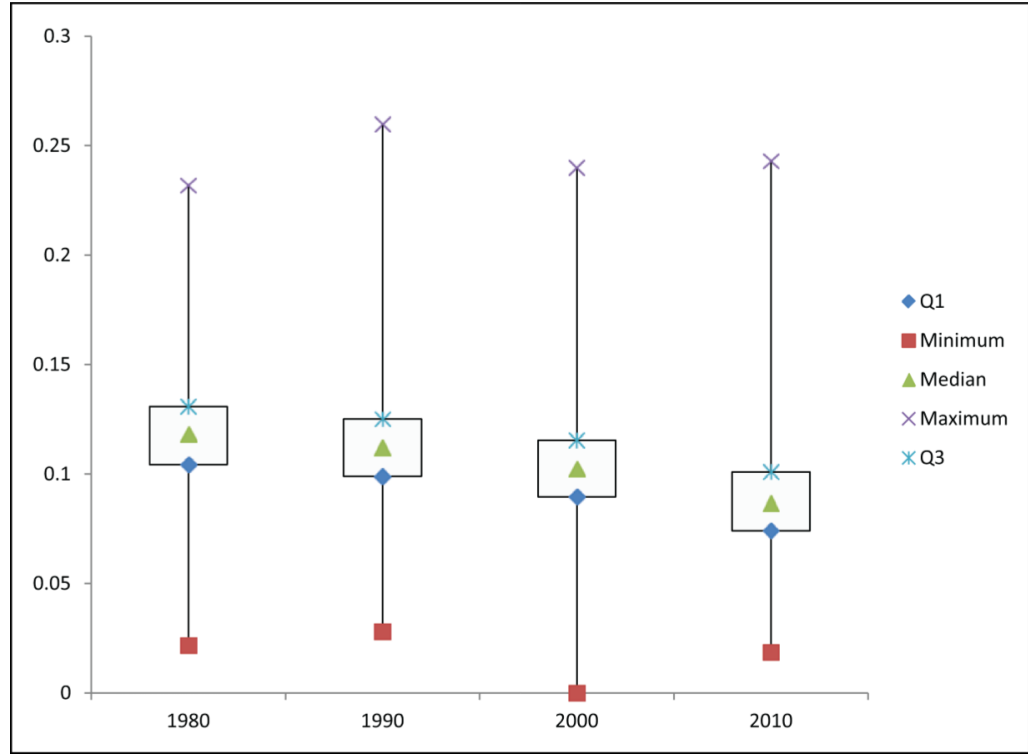

Figure 1.

Box and whisker plots for proportion of county population that is a veteran: 1980-2010. 


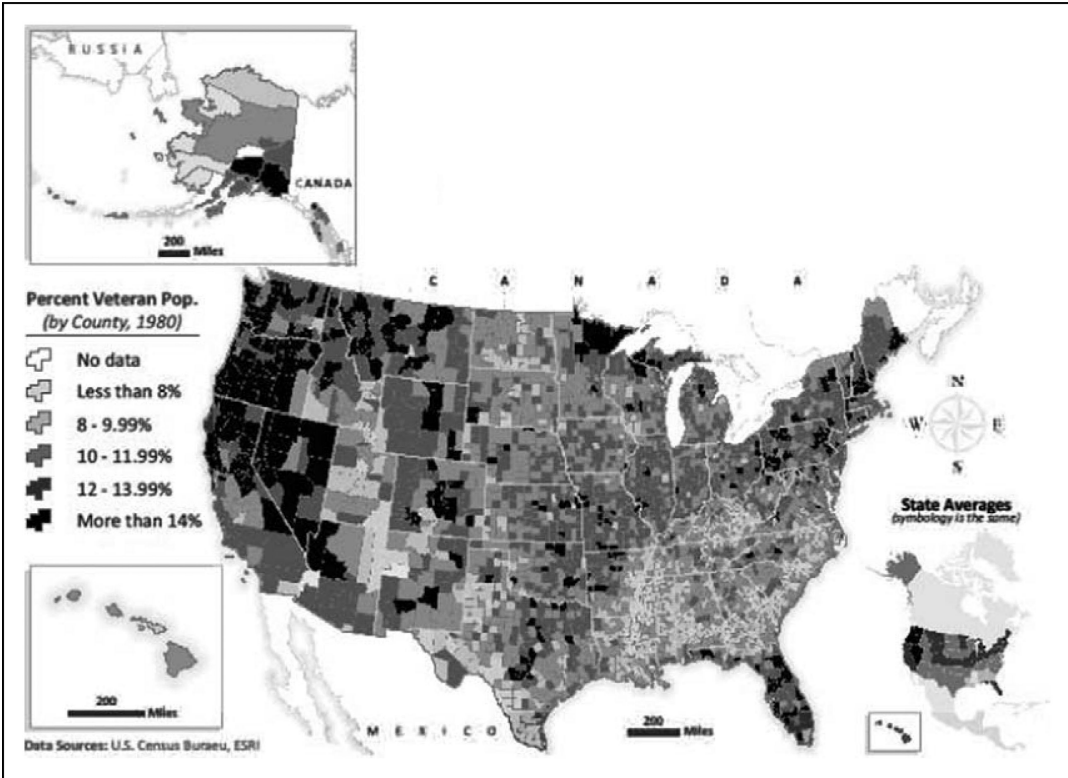

Figure 2.

Percentage of county population that is a veteran, 1980 . 


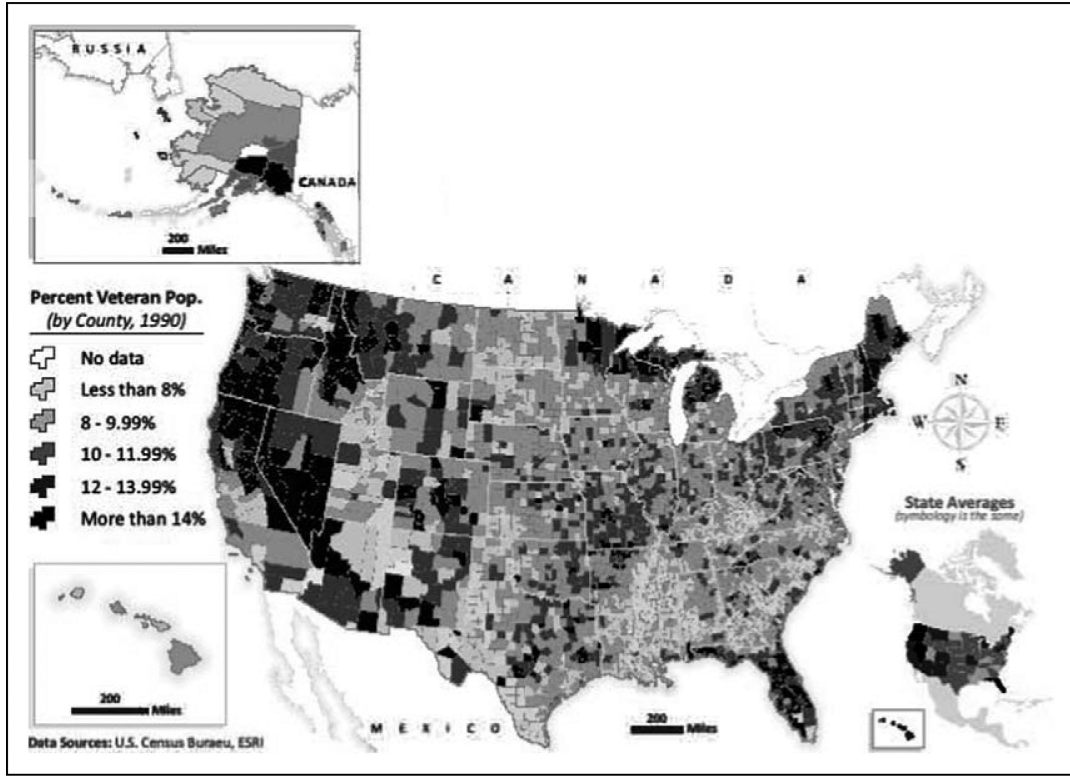

Figure 3.

Percentage of county population that is a veteran, 1990. 


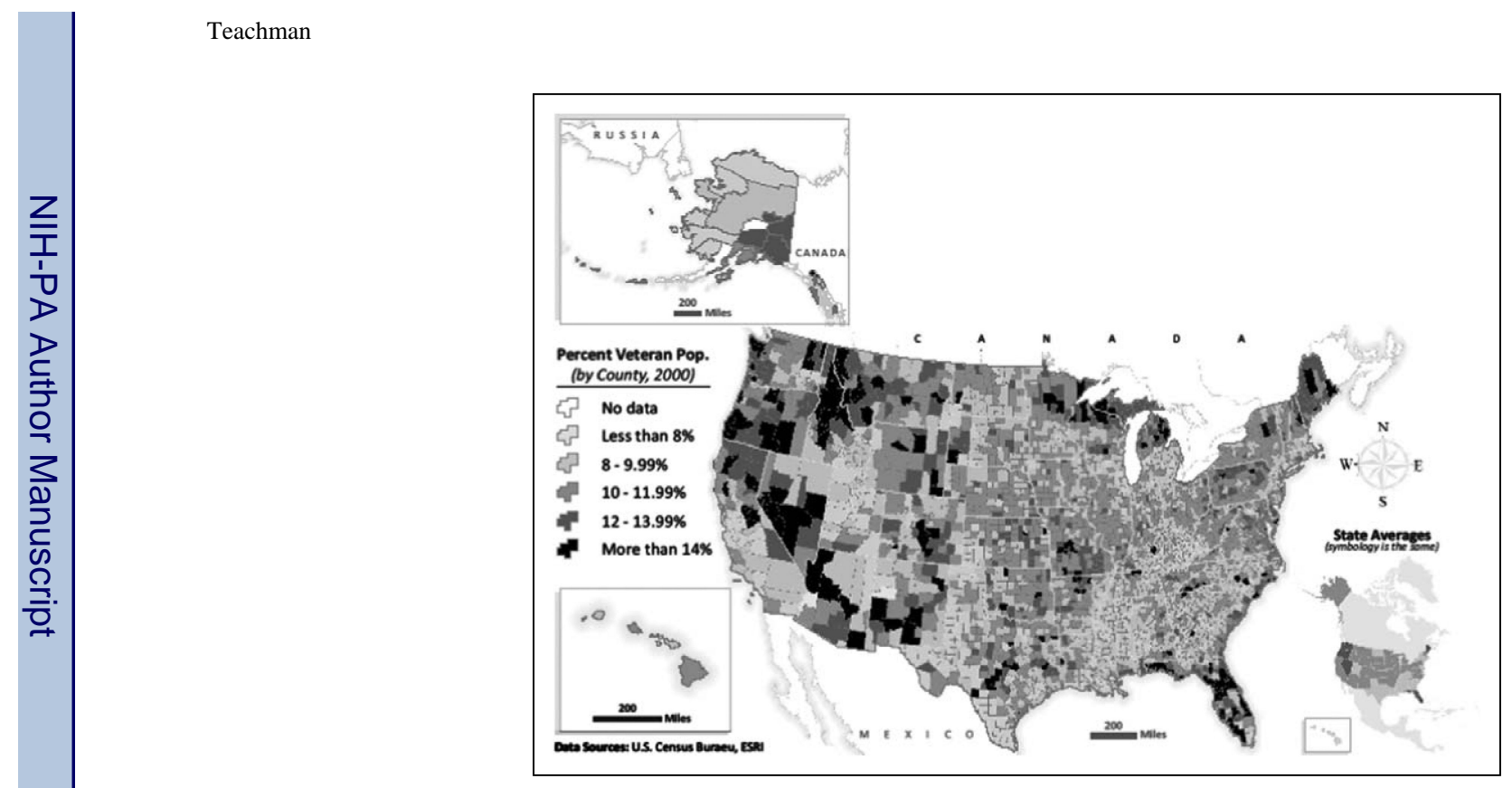

Figure 4.

Percentage of county population that is a veteran, 2000. 


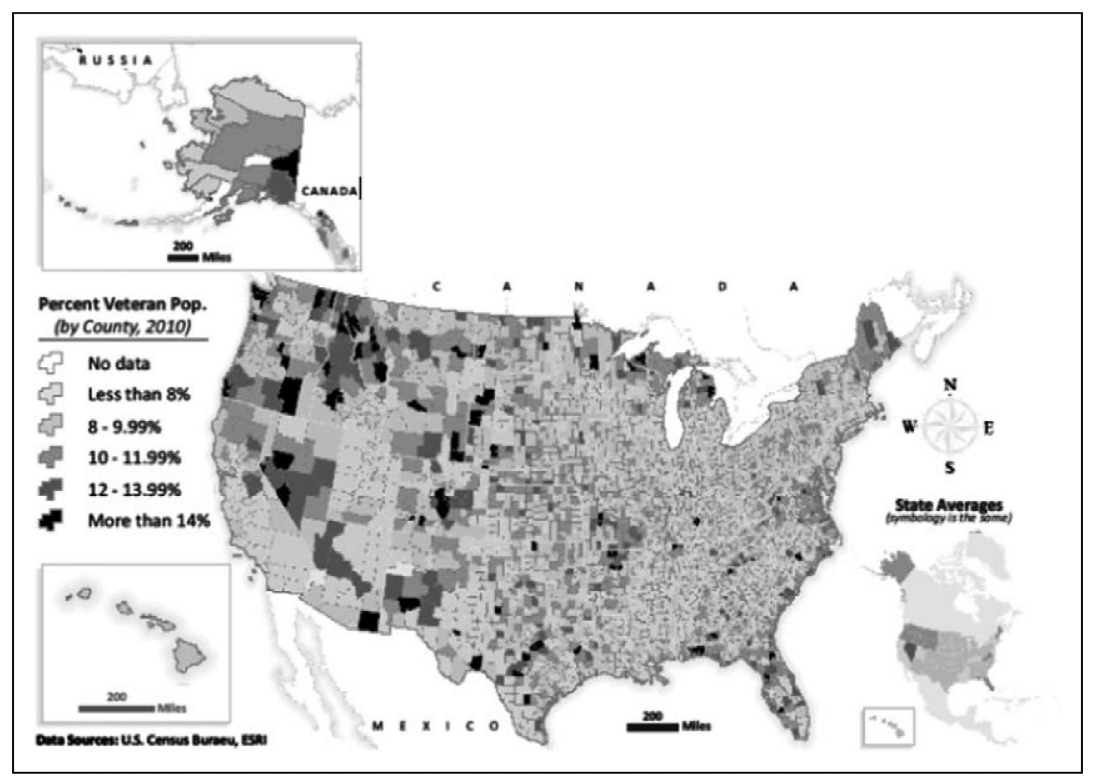

Figure 5.

Percentage of county population that is a veteran, 2010. 


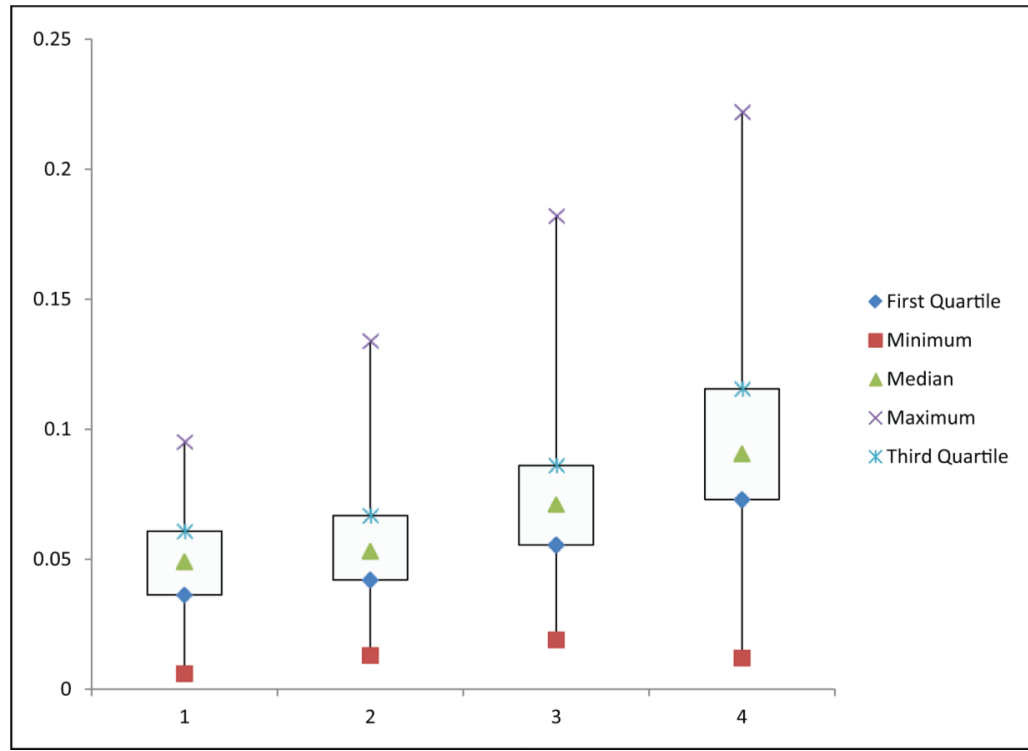

Figure 6.

Box and whisker plots for indices of dissimilarity for veteran status for states: 1980-2010. 


\section{Table 1}

Median and First and Third Quartiles for Proportion of a County that Is Veteran by Size of County: 19802010

\begin{tabular}{|c|c|c|c|c|}
\hline Estimate & 1980 & 1990 & 2000 & 2010 \\
\hline \multicolumn{5}{|l|}{ Overall } \\
\hline Q3 & .131 & .125 & .115 & .101 \\
\hline Median & .118 & .112 & .102 & .087 \\
\hline Q1 & .104 & .099 & .089 & .074 \\
\hline$n$ & 3131 & 3131 & 3131 & 3131 \\
\hline \multicolumn{5}{|c|}{ First quartile of counties by size } \\
\hline Q3 & .129 & .125 & .119 & .110 \\
\hline Median & .115 & .110 & .106 & .095 \\
\hline Q1 & .101 & .097 & .092 & .080 \\
\hline$n$ & 797 & 783 & 783 & 783 \\
\hline \multicolumn{5}{|c|}{ Second quartile of counties by size } \\
\hline Q3 & .126 & .122 & .114 & .101 \\
\hline Median & .114 & .109 & .101 & .088 \\
\hline Q1 & .097 & .094 & .089 & .074 \\
\hline$n$ & 769 & 783 & 772 & 783 \\
\hline \multicolumn{5}{|c|}{ Third quartile of counties by size } \\
\hline Q3 & .127 & .123 & .114 & .098 \\
\hline Median & .117 & .112 & .101 & .086 \\
\hline Q1 & .104 & .099 & .090 & .075 \\
\hline$n$ & 782 & 783 & 794 & 783 \\
\hline \multicolumn{5}{|c|}{ Fourth quartile of counties by size } \\
\hline Q3 & .137 & .129 & .114 & .094 \\
\hline Median & .128 & .116 & .101 & .080 \\
\hline Q1 & .115 & .106 & .089 & .068 \\
\hline$n$ & 783 & 782 & 782 & 782 \\
\hline
\end{tabular}


Table 2

Number of Counties with Percentage of Veterans Greater than 10 and 15: 1980-2010

\begin{tabular}{lrrrr}
\hline Category & $\mathbf{1 9 8 0}$ & $\mathbf{1 9 9 0}$ & $\mathbf{2 0 0 0}$ & $\mathbf{2 0 1 0}$ \\
\hline Counties with $>10 \%$ veterans & 2,509 & 2,308 & 1,722 & 828 \\
Counties with $>15 \%$ veterans & 145 & 184 & 108 & 49 \\
Counties with $>15 \%$ veterans and population $>100,000$ & 20 & 24 & 23 & 9 \\
\hline
\end{tabular}


Table 3

Median and First and Third Quartiles for Index of Dissimilarity by Size of County: 1980-2010

\begin{tabular}{lcccc}
\hline Estimate & $\mathbf{1 9 8 0}$ & $\mathbf{1 9 9 0}$ & $\mathbf{2 0 0 0}$ & $\mathbf{2 0 1 0}$ \\
\hline Overall & .064 & .083 & .111 & .144 \\
First quartile of counties by size & .086 & .094 & .092 & .104 \\
Second quartile of counties by size & .085 & .092 & .092 & .106 \\
Third quartile of counties by size & .072 & .079 & .084 & .092 \\
Fourth quartile of counties by size & .057 & .084 & .115 & .147 \\
\hline
\end{tabular}

